\title{
Tolerability and Patient/Physician Satisfaction with Subcutaneously Administered Methotrexate Provided in Two Formulations of Different Drug Concentrations in Patients with Rheumatoid Arthritis
}

\author{
Ulf Müller-Ladner ${ }^{*}, 1$, Karin Rockwitz ${ }^{2}$, Jan Brandt-Jürgens ${ }^{3}$, Roland Haux ${ }^{3}$, Peter Kästner ${ }^{4}$, \\ Jürgen Braun ${ }^{5}$, Winfried Demary ${ }^{6}$, Cécile Guimbal-Schmolck ${ }^{7}$, Uwe Pichlmeier ${ }^{7}$ and \\ Andreas Brandt ${ }^{7}$ for the MC-MTX.10/RH Study Group
}

${ }^{1}$ Kerckhoff-Klinik, Bad Nauheim, Germany

${ }^{2}$ Practising Rheumatologist, Goslar, Germany

${ }^{3}$ Practising Rheumatologist, Berlin, Germany

${ }^{4}$ Practising Rheumatologist, Erfurt, Germany

${ }^{5}$ Rheumazentrum Ruhrgebiet, Herne, Germany

${ }^{6}$ Practising Rheumatologist, Hildesheim, Germany

${ }^{7}$ Medac Gesellschaft für klinische Spezialpräparate mbH, Hamburg, Germany

\begin{abstract}
Objectives: To determine preference, satisfaction, usability and local tolerability by patients, physicians and study nurses of two subcutaneously administered methotrexate (MTX) formulations of different concentrations.

Methods: This was an open-label, comparative, within-patient controlled, multicentre study of 132 patients with rheumatoid arthritis (RA). MTX treatment consisted of $20 \mathrm{mg} /$ week administered as a medium-concentration formulation (MC) $(2.0 \mathrm{ml}$ of $10 \mathrm{mg} / \mathrm{ml}$ solution in prefilled syringe; separate needle) compared to a novel high-concentration formulation (HC) $(0.4 \mathrm{ml}$ of $50 \mathrm{mg} / \mathrm{ml}$ in prefilled syringe; pre-attached needle). Each treatment was given for three weeks. Questionnaires and visual analogue scales were used to measure outcomes.

Results: At the end of the study, 93\% of the patients preferred HC over MC as further treatment. Overall assessment of HC was "good" or "very good" in $90.6 \%$ vs $34.4 \%$ in MC-treated patients. Physician's and patients global assessment of syringe usability showed highly statistically significant differences $(P<0.0001)$ in favour of HC. Overall assessment by study nurses' and investigators' was "good" $(18.8 \%)$ or "very good" $(81.2 \%)$ for HC and "good" in $31.3 \%$ or "very good" in $12.5 \%$ for $\mathrm{MC}$, and no preference in $50 \%$. Local tolerability improved slightly also with $\mathrm{HC}$.

Conclusions: The total smaller volume of administered drug and the improved usability of a pre-attached needle in combination with a smaller prefilled syringe resulted in preference of the patients of HC over MC. The slightly improved local tolerability may also have added to this preference. This assessment was confirmed by similar assessments made by healthcare professionals.
\end{abstract}

Eudra-CT number: 2007-003591-19.

Keywords: Methotrexate, subcutaneous injection, prefilled syringe, rheumatoid arthritis.

\section{INTRODUCTION}

In the past decade, low-dose methotrexate (MTX) has become the disease-modifying antirheumatic drug of choice in the treatment of rheumatoid arthritis (RA). Subcutaneously (SC) administered MTX is well absorbed, appears to overcome the problems associated with oral administration, including variable absorption and saturation of the absorption mechanism with increasing doses, and is

*Address correspondence to this author at the Kerckhoff-Klinik GmbH, Department of Rheumatology and Clinical Immunology, Benekestrasse 2-8, D-61231 Bad Nauheim, Germany; Tel: + 49-6032-9962101; Fax: + 496032-9962104; E-mail: u.mueller-ladner@kerckhoff-klinik.de well tolerated [1]. Recent studies have also confirmed the improved usability and tolerability of subcutaneous application [2-4], in particular in comparison to intramuscular injection [2]. However, several patients still experience problems to apply several millilitres of liquid MTX every week and report also local side effects associated with the injected volume.

A 6-month, prospective, randomized, double-dummy trial compared the efficacy and safety of SC versus oral administration of MTX in 384 patients with RA [5]. Patients were randomly assigned to receive $15 \mathrm{mg} /$ week of MTX either orally (two $7.5 \mathrm{mg}$ tablets) or SC (prefilled syringe containing $10 \mathrm{mg} / \mathrm{ml}$ ). After 6 months, significantly more 
patients treated with SC MTX than with oral MTX showed ACR20 (78\% vs 70\%) and ACR70 (41\% vs 33\%) responses. Patients with disease duration $\geq 12$ months had even higher ACR20 response rates (89\% for SC administration and $63 \%$ for oral). Tolerability did not differ between the two groups.

In a phase I study, 12 healthy male subjects received $15 \mathrm{mg}$ MTX SC either as $50 \mathrm{mg} / \mathrm{ml}$ solution or as a $10 \mathrm{mg} / \mathrm{ml}$ concentration. Both concentrations were shown to be bioequivalent with regard to AUC (medac, data on file). However, the rate of absorption expressed by $\mathrm{C}_{\max }$ was different with higher $\mathrm{C}_{\max }$ concentrations achieved after administration of the higher concentrated solution. For the metabolite 7-hydroxy-MTX, similarity in rate and extent of absorption for SC administration was confirmed. Because of the bioequivalence of AUC of both concentrations, no difference in the efficacy and the safety of the two formulations was expected. Local tolerability was similar in both groups. Only three cases of mild erythema were observed (one with the concentration of $50 \mathrm{mg} / \mathrm{ml}$ and two with the concentration of $10 \mathrm{mg} / \mathrm{ml}$ ). All events occurred immediately after injection and resolved within 2 hours after injection.

The objectives of the subsequent study were the direct comparisons of local tolerability, usability, satisfaction and preference of two MTX solutions with different concentrations after $\mathrm{SC}$ administration in a larger number of patients with RA.

\section{STUDY PARTICIPANTS AND METHODS}

\section{Objectives}

The primary study objective was to assess the overall preference of RA patients for continuous MTX treatment with either the medium-concentration formulation (MC) $(2.0$ $\mathrm{ml}$ of $10 \mathrm{mg} / \mathrm{ml}$ solution; need to apply needle) or the highconcentration formulation (HC) $(0.4 \mathrm{ml}$ of $50 \mathrm{mg} / \mathrm{ml}$ prefilled syringe; pre-attached needle) by repeated SC injections.

Secondary objectives included satisfaction, usability and local tolerability assessed by patients, physicians and study nurses.

\section{Study Design}

This open, comparative, within-patient controlled, multicentre study enrolled 132 patients at 16 centres in Germany between November 2007 and November 2008. Patient enrolment by centre ranged between 1 and 24 patients. Patients received $20 \mathrm{mg}$ MTX administered SC via MC (2 $\mathrm{ml}$ of the $10 \mathrm{mg} / \mathrm{ml}$ solution) once weekly for 3 weeks followed by $\mathrm{HC}(0.4 \mathrm{ml}$ of the $50 \mathrm{mg} / \mathrm{ml}$ solution) for another three weeks. The physicians or the study nurses performed the first injection of every type of syringe $\left(1^{\text {st }}\right.$ and $4^{\text {th }}$ injection within the study), the following two injections of every type of syringe were performed by the patients themselves $\left(2^{\text {nd }}, 3^{\text {rd }}, 5^{\text {th }}\right.$ and $6^{\text {th }}$ injection within the study). Questionnaires and visual analogue scales were used to document satisfaction, usability and local tolerability. Safety laboratory testing (haematology and biochemistry) were performed at baseline, after 3 weeks and at the end of the study.

\section{Patients}

The study included patients with a diagnosis of RA according to the ACR criteria [6]. Patients were 18 to 75 years old and had received oral MTX- which is among parenteral application also in accordance with national recommendations for treatment of RA [7] - for at least 6 weeks prior to study start and required an intensified therapy due to remaining RA activity (DAS28 > 2.6). After study termination every patient received appropriate RA treatment at the discretion of the investigator.

The main exclusion criteria were: prior treatment with parenteral MTX or biologicals; concomitant treatment with another DMARD or a biological; renal insufficiency (serum creatinine $>1.5 \times \mathrm{ULN}$ ); liver function test abnormalities (AST or ALT $>2 \times$ ULN, bilirubin $>5 \mathrm{mg} / \mathrm{dl}$ ); impaired haematopoiesis (platelets $<100 \times 10^{9} / 1$, leukocytes $<3.5 \times$ $10^{9} / \mathrm{l}$ ), anaemia (haemoglobin $<10 \mathrm{~g} / \mathrm{dl}$ ); severe acute or chronic infections; malignant disease; alcohol or drug addiction; history of generalised allergic reactions or serious adverse reactions to the study medication or other components of the injection solution; women with childbearing potential without reliable contraception; men who had a partner with child-bearing potential and did not use a condom or a cervical cap/diaphragm with spermicide during the study and for at least 6 months thereafter; pregnant or breast-feeding women; any other subcutaneously administered drugs (e.g. insulin, heparin); concurrent vaccination with live vaccines.

Previous therapy with other DMARDs and concomitant therapy with nonsteroidal antirheumatic drugs or corticosteroids were permitted during the study: combination therapy with one or more DMARDs or a biological immunomodulator (e.g. TNF- $\alpha$ blockers); drugs causing folate deficiency (e.g. sulfonamides, trimethoprim-sulfamethoxazole); live-virus vaccinations. Patients were allowed to receive oral folic acid once a week, 24 hours after the MTX dose, with the dose to remain constant throughout the study.

\section{Assessment of Patient-Reported, Physician-Reported and Study Nurse/Physician-Reported Outcomes}

Table 1 summarises questions and answers concerning patient-reported, physician-reported and study nurse/physician-reported outcomes.

\section{Assessment of Safety}

All patients who received at least one dose of study medication were evaluated for the occurrence of adverse events, serious adverse events and clinical laboratory abnormalities. Severity of adverse events was assessed by the investigator as mild, moderate, severe and lifethreatening whereas clinical laboratory values were judged with respect to clinical significance.

\section{Study Medication}

Study drug consisted of the commercially available MTX medium-concentration formulation $(10 \mathrm{mg} / \mathrm{ml}$ solution; need to apply a needle; metex ${ }^{\circledR}$ in Germany, metoject ${ }^{\circledR}$ in other countries, manufacturer: medac Gesellschaft für klinische Spezialpräparate $\mathrm{mbH}$, Hamburg, Germany) and a prefilled 
Table 1. Preference and Usability Outcomes*

\begin{tabular}{|l}
\hline Patient-Reported Outcomes \\
\hline Overall preference (primary endpoint) \\
"Which of the pre-filled syringes would you prefer from now on?"
\end{tabular}

\section{Patient satisfaction}

"How would you assess, in summary, the small/large syringe at the end of the study?"

Five categories were suggested: "very poor", "poor", "no preference", "good" and "very good".

Syringe with or without pre-attached needle

"How do you like the pre-attached needle (small syringe) in comparison to one that still has to be attached (large syringe)?"

Five categories were suggested: "great disadvantage", "disadvantage", "no difference", "advantage", and "great advantage".

\section{Usability of syringe volume}

"Do you feel comfortable with the fact that the injection liquid is five times less in the small syringe than in the large syringe?"

Five possible answers were suggested: "fully disagree", "disagree", "indifferent", "agree" and "fully agree".

\section{Local tolerability}

Occurrence of erythema, swelling, itching, pain and haematoma assessed as "none", "mild", "moderate" or "severe".

Usability of the $10 \mathrm{mg} / \mathrm{ml}$ syringe at the $2^{\text {nd }}$ and $3^{\text {rd }}$ injection (MC formulation) and of the $50 \mathrm{mg} / \mathrm{ml}$ syringe at the $5^{\text {th }}$ and $6^{\text {th }}$ injection (HC formulation)

Rated on a visual scale from 0 (not convenient $=0 \mathrm{~mm})$ to $10($ very convenient $=100 \mathrm{~mm})$.

\section{Physician-Reported Outcomes}

Usability of the $10 \mathrm{mg} / \mathrm{ml}$ syringe at the $1^{\text {st }}$ injection (MC formulation) and of the $50 \mathrm{mg} / \mathrm{ml}$ syringe at the $4^{\text {th }}$ injection (HC formulation)

Rated on a visual scale from 0 (not convenient $=0 \mathrm{~mm}$ ) to 10 (very convenient $=100 \mathrm{~mm}$ ).

\section{Local tolerability}

Occurrence of erythema, swelling, itching, pain and haematoma assessed as "none", "mild", "moderate" or "severe".

\section{Study Nurse/Physician-Reported Outcomes}

Syringe with or without pre-attached needle

"How do you like the pre-attached needle (small syringe) in comparison to the one which still has to be attached (large syringe)?"

Five categories were suggested: "great disadvantage", "disadvantage", "no difference", "advantage", and "great advantage".

\section{Usability of syringe volume}

"Do you feel comfortable with the fact that the injection liquid is five times less in the small syringe than in the large syringe?"

Five possible answers were suggested: “fully disagree", "disagree", "indifferent", "agree" and "fully agree".

\section{Overall assessment of the small prefilled syringe}

Five categories were suggested: "very poor", "poor", "no preference", "good" and "very good".

Overall assessment of the large prefilled syringe

Five categories were suggested: "very poor", "poor", "no preference", "good" and "very good".

syringe MTX high-concentration formulation $(50 \mathrm{mg} / \mathrm{ml}$ solution; pre-attached needle) (Fig. 1); both formulations were provided by medac $\mathrm{GmbH}$, Germany.

\section{Statistical Analysis}

The primary objective, i.e. the proportion of patients deciding in favour of the $\mathrm{HC}$ syringe, was subjected to statistical testing by applying a two-sided one-group chisquare test on a significance level of $5 \%$. For sample size estimation, sufficient power for the statistical test was required to detect an increase of the rate of patients deciding to use the HC syringe for future MTX treatment to at least $70 \%$. A one-group chi-square test with a 5\% two-sided significance level would have $90 \%$ power to detect the difference between the null hypothesis rate of $55 \%$ and the alternative rate of $70 \%$ with a sample size of 110 patients.

To assess the local tolerability at the site of injection, frequency distributions of mild, moderate and severe signs and symptoms of swelling, itching, erythema, haematoma and pain were presented. Treatment-specific differences between ordinal data were evaluated using Wilcoxon signedrank tests on an explorative perspective. All other parameters were analysed descriptively using robust measures of location and dispersion such as medians and $1^{\text {st }}(\mathrm{Q} 1)$ and $3^{\text {rd }}$ quartiles (Q3). 


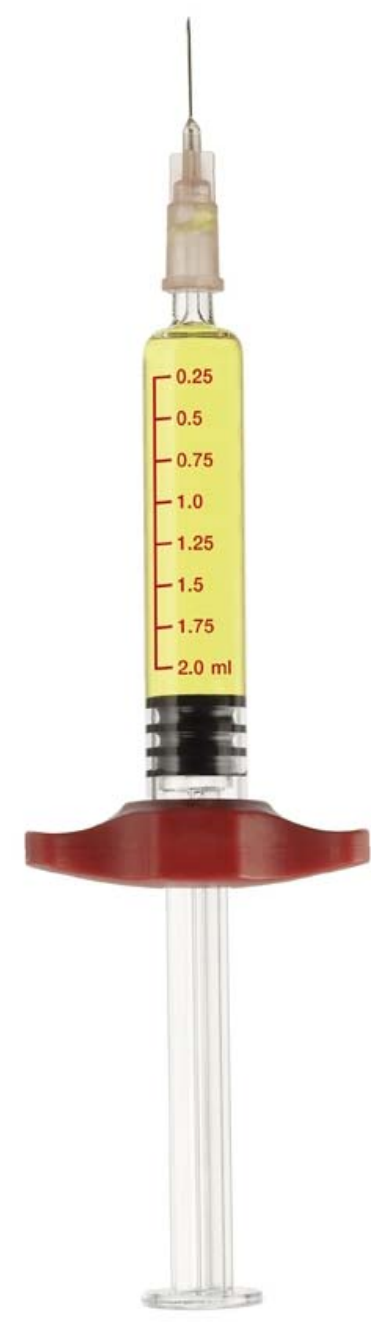

MTX $10 \mathrm{mg} / \mathrm{ml}$

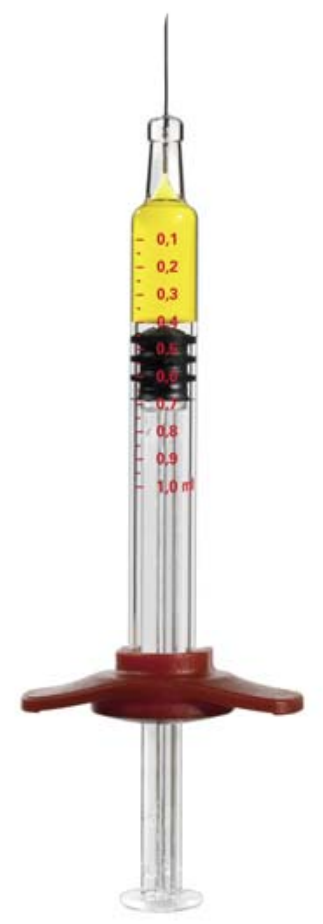

MTX $50 \mathrm{mg} / \mathrm{ml}$
Fig. (1). Comparison of the methotrexate prefilled syringe $10 \mathrm{mg} / \mathrm{ml}$ and $50 \mathrm{mg} / \mathrm{ml}$ true to scale. MTX=methotrexate.

\section{Ethics}

The study was performed in accordance with the Good Clinical Practice guidelines recommended by the International Conference on Harmonization (ICH) of Technical Requirements. Ethics committees relevant to the respective study sites approved the study protocol. Written informed consent was obtained from all patients.

\section{Funding}

The study was supported by medac Gesellschaft für klinische Spezialpräparate mbH, Hamburg, Germany.

\section{RESULTS}

\section{Patient Characteristics}

Of the 132 patients enrolled, one was excluded from the safety-analysis set (due to missing study visits $\left(1^{\text {st }}, 2^{\text {nd }}\right.$ and $4^{\text {th }}$ injection) and lack of any source data) and additional 3 were excluded from the full-analysis set (due to injection of merely one type of syringe). Of the 128 patients included in the full-analysis set, 34 were men and 94 women. Median age was 56 years (range: 18 to 75 years), median weight $78 \mathrm{~kg}$ (range: 49 to $116 \mathrm{~kg}$ ) and median body height $165 \mathrm{~cm}$ (range: 150 to $188 \mathrm{~cm}$ ). Median baseline Disease Activity Score of 28 joints (DAS28) was 4.3 (range 2 to 8 ) and median duration of RA in the patients was 3 years (range: 1 to 39 years). Sixty-three $(49.2 \%)$ patients had previously received MTX treatment at dosages ranging between 7.5 to $25 \mathrm{mg} /$ week and differed from those dosages given at study start. $85.1 \%$ of the patients received MTX dosages of 15 or $20 \mathrm{mg} /$ week (6 patients received more than $20 \mathrm{mg}$ oral MTX, 1 patient received $25 \mathrm{mg}$, the other ones $22.5 \mathrm{mg}$ ).

\section{Efficacy}

\section{Patient-Reported Outcomes}

The primary efficacy variable was to quantify the decision of the patient for future MTX treatment $(50 \mathrm{mg} / \mathrm{ml}$ syringe vs $10 \mathrm{mg} / \mathrm{ml}$ syringe) following repeated $\mathrm{SC}$ injections of both formulations. At the end of the study, $93.0 \%$ of all patients stated that they would prefer the HC formulation compared to $2.3 \%$ of the patients expressing a preference for the MC formulation (95\% confidence interval: $[87.1 \% ; 96.7 \%])$. The result was highly statistically significant $(P<0.0001)$.

At the end of the study, overall assessment of the patients of the HC formulation was "good" and "very good" in $90.6 \%$ of the patients compared to $1.6 \%$ with a "poor" and "very poor" overall assessment. The patients' overall assessment of the MC formulation was "good" and "very good" in $34.4 \%$ of the patients compared to $17.2 \%$ with a "poor" and "very poor" overall assessment (Fig. 2). This advantage in favour of the $\mathrm{HC}$ formulation was statistically significant $(P<0.0001)$.

$89.1 \%$ of the patients assessed the usability of having a pre-attached needle with the small syringe (HC formulation) as an "advantage" and "great advantage" and $3.1 \%$ as a "disadvantage" and "great disadvantage".

$87.5 \%$ of the patients reported that the smaller volume in the $\mathrm{HC}$ formulation was more suitable ("agree" and "fully agree") compared to the larger volume with the $\mathrm{MC}$ formulation. $1.6 \%$ of the patients disagreed in this regard.

Using a visual analogue scale, patient's global assessment of syringe usability was $63.5 \mathrm{~mm}$ (Q1-Q3: 4992) after MC administrations which increased significantly to $95.0 \mathrm{~mm}(\mathrm{Q} 1-\mathrm{Q} 3:$ 85-99) after administration of the HC formulation ( $\mathrm{P}<0.0001)$.

\section{Physician-Reported Outcomes}

Using a visual analogue scale, physician-reported global assessment of syringe usability was $82.0 \mathrm{~mm}$ (Q1-Q3: 59$100)$ at the time of administration of the $\mathrm{MC}$ formulation. A significant increase in to $96.0 \mathrm{~mm}(\mathrm{Q} 1-\mathrm{Q} 3:$ 86-100) was observed at time of $\mathrm{HC}$ administration $(P<0.0001)$.

\section{Study Nurse/Physician-Reported Outcomes}

All study nurses and physicians assessed the usability of having a pre-attached needle with the small syringe (HC formulation) as an "advantage" or "great advantage". 


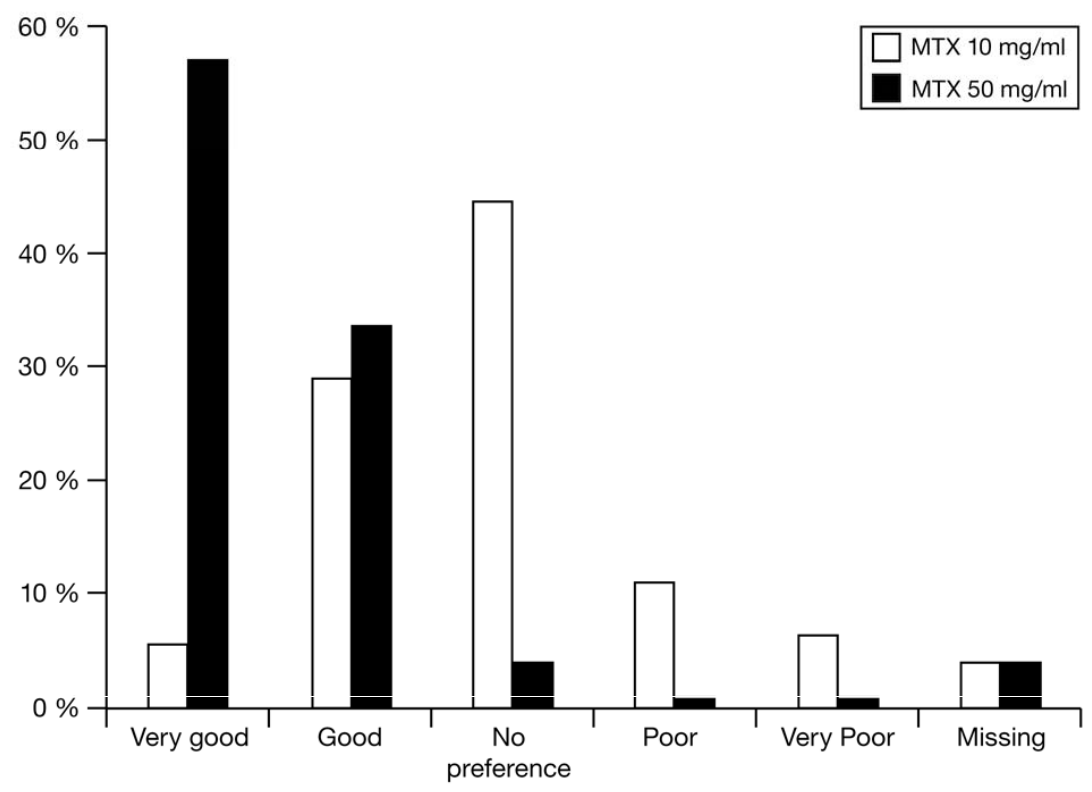

Fig. (2). Patients' overall assessment of methotrexate prefilled syringe $10 \mathrm{mg} / \mathrm{ml}$ and $50 \mathrm{mg} / \mathrm{ml}$.

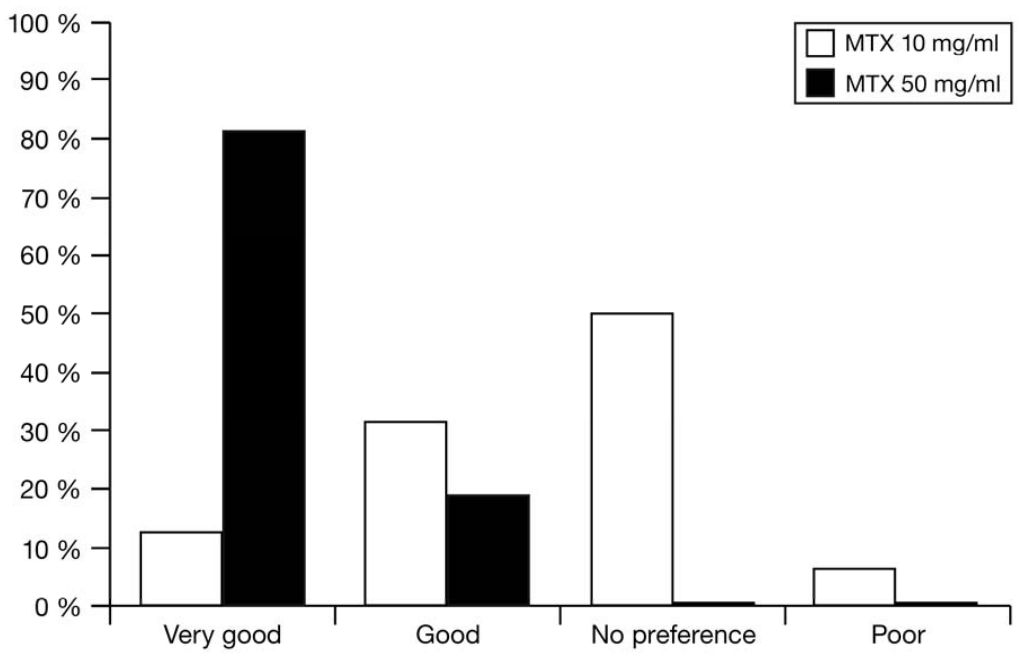

Fig. (3). Study nurses' and physicians' overall assessment of methotrexate prefilled syringe $10 \mathrm{mg} / \mathrm{ml} \mathrm{and} 50 \mathrm{mg} / \mathrm{ml}$.

$87.5 \%$ found that the smaller volume in the $\mathrm{HC}$ formulation was more suitable ("agree" and "fully agree") compared to the larger volume with the MC formulation. $12.5 \%$ saw no difference in this regard.

At the end of the study, study nurses' and investigators' overall assessment of the HC formulation was "good" $(18.8 \%)$ and "very good" $(81.2 \%)$. The overall assessment of the MC formulation was "good" in $31.3 \%$ of cases, "very good" in $12.5 \%$ and no preference in $50 \%$ (Fig. 3 ).

\section{Safety}

Adverse events were coded according to the Medical Dictionary for Regulatory Affairs (MedDRA). Adverse events were reported in $25(19.1 \%)$ of the 131 patients valid for safety analysis. The number of patients experiencing adverse events was $14(10.7 \%)$ and $15(11.5 \%)$ with MC and $\mathrm{HC}$ formulation, respectively (Table 2 ).

All adverse events expect the one documented within the system organ class "Injury, poising and procedural complications" were judged to be at least possibly drugrelated. The most frequent adverse events and drug-related adverse events were gastrointestinal disorders $(6.1 \%)$, investigations $(3.8 \%)$ and general disorders and administration site conditions irritations (3.1\%). Most adverse events were of mild and moderate intensity. No relevant differences were observed between the two MTX formulations with the exception of five cases of mild and moderate increases in liver enzymes documented within the 
Table 2. Adverse Events

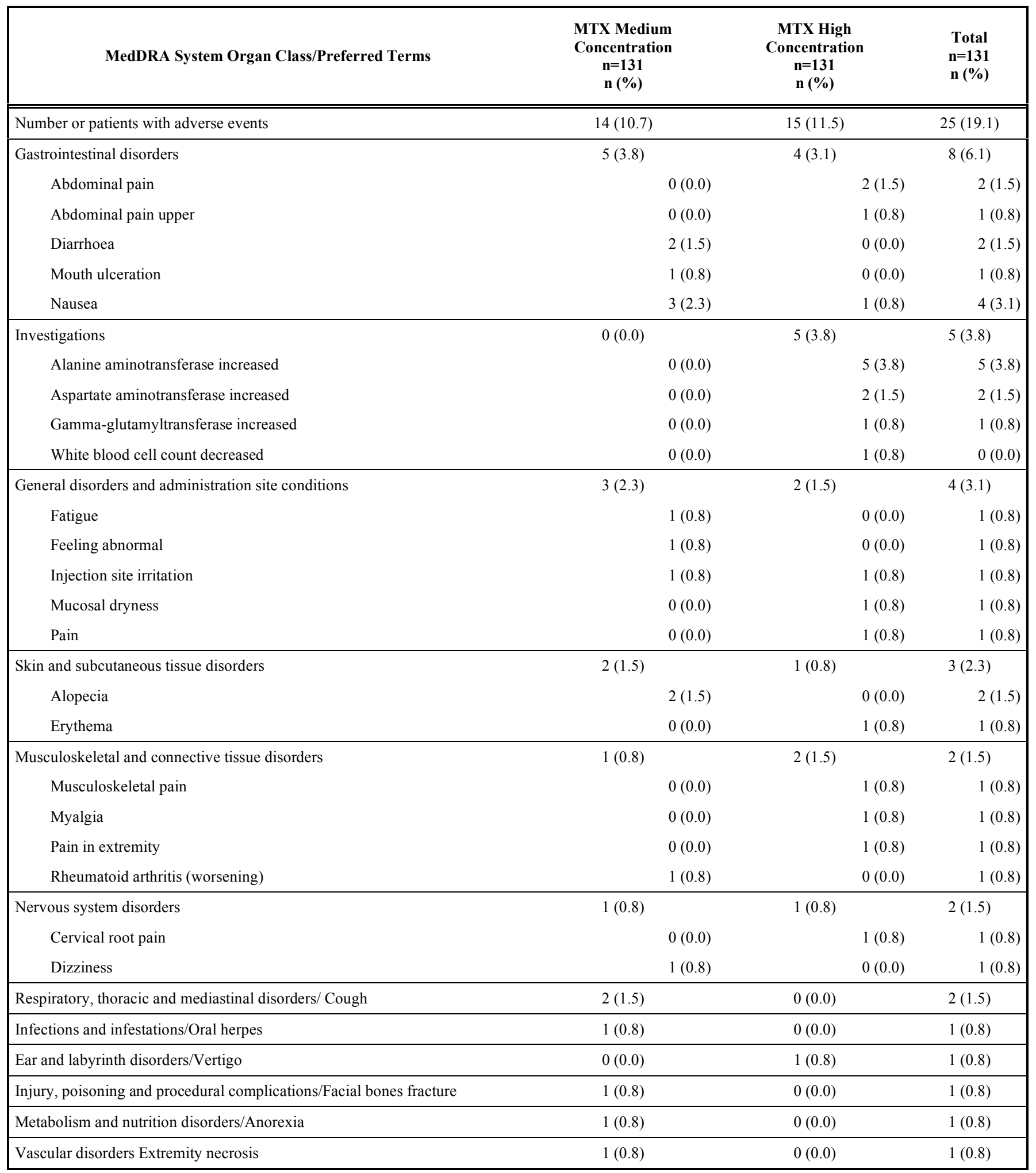

system organ class investigations occurring during $\mathrm{HC}$ treatment compared to no cases during MC treatment.

Three serious adverse events were reported: One occurred during HC-treatment phase two days after the $5^{\text {th }}$ injection (cheek bone fracture) and two others (back pain and left ear mastoiditis) within 28 days after the final examination. All events were considered unrelated to study medication by the investigator.

Three subjects discontinued study participation due to adverse events. These included coughing, dizziness and nausea/sicca symptoms/pain. All events were non-serious and considered as possibly related to study medication. 
With regard to overall local tolerability including erythema, swelling, itching, pain and haematoma at the injection site, $\mathrm{HC}$ treatment was slightly better tolerated than MC treatment. Physicians' assessment of the injection site showed an absence of erythema with $\mathrm{HC}$ treatment in $79.7 \%$ of patients compared to $71.1 \%$ with MC treatment, which was statistically significant $(P=0.0123)$ and tended to be confirmed by patients' assessment.

For all laboratory categories (haematology and biochemistry), mean parameter changes were minor including those of liver function tests. Except for a mean decrease in CRP by $4 \mathrm{mg} / \mathrm{l}$, mean changes were of no clinical relevance.

\section{DISCUSSION}

The results of the study show that repeat dosing of the novel high-concentration (HC) MTX solution available in a prefilled syringe with a pre-attached needle yields a significantly better acceptance by patients and healthcare professionals than the medium-concentration (MC) solution with a syringe to which the needle still has to be attached.

The MTX formulations differ also considerably with regard to usability and overall preference in numerous patients with RA who self-administered the prefilled MTX syringes. At the end of the study $93 \%$ of the patients preferred $\mathrm{HC}$ over $\mathrm{MC}$ as further treatment. Physicians' and patients' global assessments of syringe usability showed also highly statistically significant differences $(P<0.0001)$ in favour of the $\mathrm{HC}$ formulation.

Reasons for this preference also include a smaller volume of administered drug, which improves the comfort of injection and may represent a psychological benefit for the patient. In addition, the pre-attached needle (HC formulation) allows a safer handling in comparison to the MC syringe, for which the needle must first be attached to the syringe body.

A within patient-controlled design was considered the most appropriate approach to determine whether the switch to the newly available $\mathrm{HC}$ treatment has the ability to increase patient's satisfaction of subcutaneous MTX treatment compared to the previously available $\mathrm{MC}$ treatment. Due to different sizes of syringes blinding of patients and nurses was not feasible within this trial. However, the study results may be biased due to the fact that the treatment sequence was not randomized. But, looking at the huge numerical advantage of $\mathrm{HC}$, this bias can be considered to be negligible with respect to the overall study conclusion.

Differences regarding local tolerability were slightly in favour of $\mathrm{HC}$ treatment. Erythema occurred significantly less often with $\mathrm{HC}$ treatment compared to $\mathrm{MC}$ treatment. Overall patient assessment was confirmed by physician and study nurse assessments who expressed similar preferences and conclusions as the patients. In general, quantity and quality of adverse events did not differ between the two formulations to a relevant extent.

This study focused on safety and tolerability and not on efficacy. However, as the superior efficacy of SC administered MTX has been proven in a recent 6-month, multicenter, randomized, double-blind, controlled trial in comparison to oral MTX in 384 MTX-naïve patients with active RA [5], similar clinical results can be expected for the novel HC formulation. Parenteral MTX treatment is in accordance with current practice guidelines which recommend to consider a switch to the intramuscular or SC route in patients with poor compliance, inadequate effectiveness, or gastrointestinal side effects $[8,9]$. Taking into account the evidence from other studies which have confirmed the improved usability and tolerability of SC administration of MTX also in comparison to intramuscular injection [2-4], the newly developed $50 \mathrm{mg} / \mathrm{ml}$ prefilled syringe appears to be a highly preferred treatment option for patients with RA in need of MTX. This is supported by the strong appreciation of the patients as well as their attending healthcare professionals for its usability and tolerability.

\section{CONCLUSIONS}

A smaller volume of administered drug, the usability of being able to use a pre-attached needle with the small prefilled syringe and an improved local tolerability have contributed to the preference of the $\mathrm{HC}$ small syringe to apply subcutaneous MTX in active RA patients. This assessment was supported by similar assessments made by physicians and study nurses. With the exception of erythema which occurred significantly less often with $\mathrm{HC}$ treatment quality and quantity of adverse events did in general not differ between the two formulations.

\section{ACKNOWLEDGSMENTS}

The authors wish to thank all patients who participated in the trial and all rheumatologists and nursing staff of the participating centres who enrolled at least 1 patient:

K. Rockwitz, Goslar; J. Brandt-Jürgens, Berlin; R. Haux, Berlin; P. Kästner, Erfurt; J. Braun, Herne; W. Demary, Hildesheim; K. Karberg, Berlin; M. Leidert, Lüneburg; U. Müller-Ladner, Bad Nauheim; H. Schulze-Koops, München; C. Fiehn, Baden-Baden; B. Heilig, Heidelberg; C. Baerwald, Leipzig; M. Fleck, Bad Abbach; J. Kuipers, Bremen; G. Gauler, Osnabrück.

The authors also wish to thank Sonja Böhm, medac $\mathrm{GmbH}$, for her excellent monitoring of the study and Martin Bornemann, who provided medical writing support on behalf of medac $\mathrm{GmbH}$.

\section{FINANCIAL DISCLOSURES/CONFLICTS OF INTEREST}

UML has received consulting and speaker fees (less than 10.000 USD) from medac GmbH. CGS, UP and AB are employees of medac $\mathrm{GmbH}$. All other authors have declared no conflicts of interest.

\section{KEY MESSAGES}

Patients, physicians and nursing staff prefer a highconcentration prefilled syringe over a medium-concentration syringe for SC administration of MTX.

Superior usability and overall satisfaction contributed to this preference. Local tolerability trended to be advantageous for $\mathrm{HC}$ and was partly significant for erythema. 


\section{REFERENCES}

[1] Balis FM, Mirro J, Jr., Reaman GH, et al. Pharmacokinetics of subcutaneous methotrexate. J Clin Oncol 1988; 6: 1882-6.

[2] Brooks PJ, Spruill WJ, Parish RC, Birchmore DA. Pharmacokinetics of methotrexate administered by intramuscular and subcutaneous injections in patients with rheumatoid arthritis. Arthritis Rheum 1990; 33: 91-4

[3] Sander O, Hübner G, Rau R. Subcutaneous MTX - a reasonable addition of established modes of administration. Z Rheumatol 1996; 55(Suppl 1): 111.

[4] Zackheim HS. Subcutaneous administration of methotrexate. J Am Acad Dermatol 1992; 26: 1008.

[5] Braun J, Kästner P, Flaxenberg P, et al. Comparison of the clinical efficacy and safety of subcutaneous versus oral administration of methotrexate in patients with active rheumatoid arthritis: Results of a six-month, multicenter, randomized, double-blind, controlled, phase IV trial. Arthritis Rheum 2008; 58: 73-81.

[6] Arnett FC, Edworthy SM, Bloch DA, et al. The American Rheumatism Association 1987 revised criteria for the classification of rheumatoid arthritis. Arthritis Rheum 1988; 31: 315-24.

[7] Wollenhaupt J, Alten R, Backhaus M, et al. Recommendations for the treatment of rheumatoid arthritis. Results from a German consensus conference: Update 2009. Akt Rheumatol 2009; 34: 2349.

[8] Pavy S, Constantin A, Pham T, et al. Methotrexate therapy for rheumatoid arthritis: Clinical practice guidelines based on published evidence and expert opinion. Joint Bone Spine 2006; 73: 388-95.

[9] Tarner IH, Manger B, Fleck M, et al. Evidence-based recommendations of a national group of experts on the use of methotrexate in inflammatory rheumatic diseases. Akt Rheumatol 2009; 34: 59-66.

(C) Müller-Ladner et al.; Licensee Bentham Open.

This is an open access article licensed under the terms of the Creative Commons Attribution Non-Commercial License (http://creativecommons.org/licenses/by-nc/ $3.0 /$ ) which permits unrestricted, non-commercial use, distribution and reproduction in any medium, provided the work is properly cited. 